\title{
CTAG1B Positive
}

National Cancer Institute

\section{Source}

National Cancer Institute. CTAG1B Positive. NCI Thesaurus. Code C142102.

An indication that CTAG1B expression has been detected in a sample. 